\title{
Characterisation of chloramphenicol resistance plasmids of Staphylococcus aureus and $S$. epidermidis by restriction enzyme mapping techniques
}

\author{
JAN M. TENNENT, J. W. MAY and R. A. SKURRAY*
}

Department of Microbiology, Monash University, Clayton, Victoria, Australia, 3168

\begin{abstract}
Summary. Chloramphenicol resistance $\left(\mathrm{Cm}^{\mathrm{r}}\right)$ plasmids pSK2 and pSK5 from Staphylococcus aureus and pSK102 and pSK103 from $S$. epidermidis have been characterised and detailed restriction endonuclease cleavage maps constructed. TaqI digestion profiles illustrated the identity of pSK 5 and pSK 102 and also revealed a high degree of similarity between these four $\mathrm{Cm}^{\mathrm{r}}$ plasmids from Australian staphylococci and three $\mathrm{Cm}^{\mathrm{r}}$ plasmids from $S$. aureus strains of geographically unrelated origin. DNA-DNA hybridisation indicated that the chloramphenicol acetyltransferase determinant carried by $\mathrm{pSK} 5 / \mathrm{pSK} 102$ could be found on other structurally-distinct $\mathrm{Cm}^{\mathrm{r}}$ plasmids. The role of $S$. epidermidis as a reservoir for $\mathrm{Cm}^{\mathrm{r}}$ plasmids found in $S$. aureus is discussed.
\end{abstract}

\section{Introduction}

Staphylococcal resistance to chloramphenicol is affected by the inducible enzyme chloramphenicol acetyltransferase (CAT) which converts the antibiotic to an inactive acetoxy-form in the presence of acetyl coenzyme A (Shaw, 1984). The cat genes of Staphylococcus aureus which encode this enzyme have previously been shown to exist on several small, multicopy plasmids of various incompatibility groups (Novick, 1976; Iordănescu et al., 1978; Wilson and Baldwin, 1978). In agreement with these observations, chloramphenicol resistance amongst Australian isolates of multiresistant $S$. aureus isolated during the period 1979-1982, was found to be exclusively plasmid-mediated. Two $\mathrm{Cm}^{\mathrm{r}}$ plasmids, pSK 2 and pSK5, each c. 4.5 kilobase pairs $(\mathrm{kb})$ in size but distinguishable on the basis of their restriction endonuclease profiles, have been identified in these strains by plasmid elimination studies and by transfer experiments (Lyon et al., 1983, 1984a and unpublished data). Furthermore, we have described pSK 102, a $\mathrm{Cm}^{\mathrm{r}}$ plasmid isolated from a clinical strain of $S$. epidermidis, which closely resembled pSK 5 (Tennent et al., 1984). Preliminary analyses therefore suggested that common $\mathrm{Cm}^{\mathrm{r}}$ plasmids may be present in Australian strains of $S$.

Received 25 Oct. 1985; revised version accepted 10 Dec. 1985.

* Correspondence and requests for offprints should be sent to $\mathrm{Dr}$ R. A. Skurray aureus and $S$. epidermidis. This paper reports the molecular characterisation of $\mathrm{Cm}^{\mathrm{r}}$ plasmids isolated from both staphylococcal species and presents restriction endonuclease and DNA-DNA hybridisation data supporting the notion that the determinants for chloramphenicol resistance have spread amongst clinical isolates of $S$. aureus and S. epidermidis.

\section{Materials and Methods}

\section{Bacterial strains and plasmids}

Clinical isolates of S. aureus (SK52 and SK429) and $S$. epidermidis (SK99 and SK356) resistant to chloramphenicol were selected from a collection of multiresistant strains obtained from Australian hospitals during the period 1979-1982.

S. aureus strain RN1305 carrying the plasmid pC221 was kindly provided by R. P. Novick (Public Health Research Institute of the City of New York). S. aureus strains carrying plasmids pUB112 and pC223 were obtained from the Bacillus Genetic Stock Center (Columbus, OH, USA). A description of the plasmids, including their host strains, is presented in table I.

Recipient strains used in DNA transfer experiments were $S$. aureus strain SA113, received from $\operatorname{Dr} S$. Iordănescu (Institute Cantucuzino, Bucharest, Romania), and strain SK982, a rifampicin- and novobiocinresistant mutant of strain SA113 selected in this laboratory (Lyon et al., 1984b). 


\section{General procedures}

The media used and the methods for the determination of antibiotic susceptibilities and minimum inhibitory concentrations (MICs), for transformation of plasmid DNA and for plasmid elimination were as described previously (Gillespie et al., 1984; Lyon et al., 1984a). Plasmid DNA was transferred to strain SK982 in mixed culture by the method of McDonnell et al. (1983). Overnight cultures of the donor and recipient strains were subcultured into fresh Brain Heart Infusion (BHI) broth (Oxoid) and incubated with aeration at $37^{\circ} \mathrm{C}$. After $6 \mathrm{~h}$, the cells were harvested, resuspended in nutrient broth and adjusted by optical density to $c .10^{7} \mathrm{cfu} / \mathrm{ml}$. One-ml volumes of donor and recipient suspensions were com-

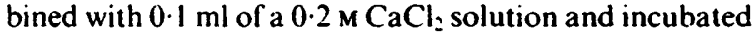
at $37 \mathrm{C}$ for $18 \mathrm{~h}$ with aeration. Samples of the mixed culture were plated onto $\mathrm{BHI}$ agar containing novobiocin $1 \mathrm{mg} / \mathrm{L}$, rifampicin $10 \mathrm{mg} / \mathrm{L}$ and chloramphenicol $16 \mathrm{mg} / \mathrm{L}$ to select $\mathrm{Cm}^{\mathrm{r}}$ transcipients. As controls in each experiment, the donor and recipient strains were each incubated singly and plated on to the selective media.

Plasmid DNA isolation, agarose gel electrophoresis and restriction endonuclease analysis

Plasmid DNA prepared from cultures of $S$. aureus and $S$. epidermidis was purified in caesium chloride-ethidium bromide density gradients as previously described (Tennent et al., 1984). Restriction endonuclease analysis of plasmid DNA with each of the restriction endonucleases (New England Biolabs. Beverley. MA 01915. USA) listed in table II was as described by Lyon et al. (1983): DNA samples were electrophoresed through Tris-acetateEDTA buffered agarose gels or Tris-borate-EDTA buffered polyacrylamide gels with either the HindIII-EcoRI fragments of bacteriophage lambda DNA or the Haelll fragments of pBR322 DNA, respectively, as standards (Sutcliffe, 1978: Daniels et al.. 1983). DNA from either gel system was transferred to nitrocellulose for hybridisation analysis by the bidirectional procedure of Smith and Summers (1980). The electroelution technique of Smith (1980) was employed to separate whole plasmids or restriction endonuclease fragments from a heterogeneous sample of DNA.

\section{Hybridisation analyis of plasmid DNA}

A DNA fragment containing part of the cat gene was prepared by electroelution after double digestion of $\mathrm{pC} 221$ with $\mathrm{Accl}$ and $\mathrm{Mhol}$. The fragment was radiolabelled with $10 \mu \mathrm{Ci}$ of $\left[\alpha-{ }^{32} \mathrm{P}\right] \mathrm{ATP}(1800 \mathrm{Ci} / \mathrm{mmole})$ by nick translation and hybridised with nitrocellulose filters carrying the target DNA as described by Maniatis et al. (1982). Washed and dried filters were then exposed to Fuji $\mathrm{RX}$ film at $-70 \mathrm{C}$ for sufficient time to produce an acceptable autoradiograph. The hybridisation experiments reported in this paper were repeated on several occasions and produced identical results.
Table I. Characteristics of chloramphenicol resistance plasmids

\begin{tabular}{|c|c|c|c|}
\hline Plasmid & $\begin{array}{l}\text { Size } \\
(\mathbf{k b})\end{array}$ & Isolated from & Reference \\
\hline pSK2 & 4.5 & S. aureus SK 52 & This paper \\
\hline pSK5 & 4.55 & S. aureus SK 429 & Lyon et al., 1983 \\
\hline pSK 102 & 4.55 & S. epidermidis SK99 & Tennent et al., 1984 \\
\hline pSK 103 & $4 \cdot 6$ & S. epidermidis SK356 & This paper \\
\hline pC221 & 4.55 & S. aureus & Projan et al., 1985 \\
\hline 3 & $4 \cdot 6$ & S. aureus & Novick, 1976 \\
\hline pUB 112 & 4.05 & S. aureus & Brückner et al., 1984 \\
\hline
\end{tabular}

\section{Results}

\section{Plasmid-mediated chloramphenicol resistance}

Purified plasmid DNA from the clinical $S$. aureus strain SK52 (table I) was used to transform the plasmid-free recipient SAl13 to chloramphenicol resistance. All $\mathrm{Cm}^{r}$ transformants were found to contain plasmid DNA equivalent in size and restriction profile to pSK2, confirming that $\mathrm{Cm}^{\mathrm{r}}$ was mediated by this plasmid.

Plasmids of $c .4 .5 \mathrm{~kb}$ were also found to mediate $\mathrm{Cm}^{\mathrm{r}}$ in clinical isolates of $S$. epidermidis such as SK99 and SK356 (table I). Plasmid pSK 102 was found to mediate this phenotype in strain SK99. as demonstrated by curing studies (Tennent et al., 1984) and by transformation to strain SAl13. Another, slightly larger, $\mathrm{Cm}^{\mathrm{r}}$ plasmid, pSK 103, was transferred from strain SK 356 to recipient SK982 in mixed culture. Once again, when plasmid DNA was isolated from the $\mathrm{Cm}^{\mathrm{r}}$ transformants and transcipients they were found to contain plasmid DNA electrophoretically indistinguishable from either pSK 102 or pSK 103, respectively.

The MIC of chloramphenicol for the $\mathrm{Cm}^{\mathrm{r}}$ clinical strains of $S$. aureus and $S$. epidermidis (table I), and for transformants and transcipients which carried the plasmids pSK2, pSK 102 or pSK103, was 60 $\mathrm{mg} / \mathrm{L}$.

\section{Restriction endonuclease analysis}

To examine the relatedness of the four phenotypically-similar plasmids from $S$. aureus and $S$. epidermidis, purified plasmid DNA was cleaved with various restriction endonucleases and the restriction profiles analysed by agarose gel electrophoresis; purified pSK2, pSK 102 and pSK 103 DNA was prepared from the transformants and transcipients described above, but pSK5 DNA was obtained by electroelution from a sample of SK429 DNA which contained two other plasmids (Lyon et al., 1983). Each of the plasmids pSK2, pSK5, pSK102 and 
Table II. Restriction sites on $\mathrm{Cm}^{r}$ plasmids

\begin{tabular}{l|ccccccccccccc}
\hline & \multicolumn{10}{c}{ Numbers of sites for restriction endonucleases* } \\
\cline { 2 - 12 } Plasmid & AccI & BgIII & BstEII & ClaI & EcoRI & HindIII & HpaII & MboI & PvuII & SalI & SacI & TaqI & XbaI \\
\hline pSK2 & 1 & 0 & 1 & 1 & 0 & 1 & 3 & 3 & 1 & 1 & 0 & 11 & 1 \\
pSK5 & 2 & 0 & 1 & 1 & 1 & 1 & 3 & 3 & 0 & 0 & 1 & 12 & 2 \\
pSK102 & 2 & 0 & 1 & 1 & 1 & 1 & 3 & 3 & 0 & 0 & 1 & 12 & 2 \\
pC221 & 2 & 0 & 1 & 1 & 1 & 1 & 3 & 3 & 0 & 0 & 1 & 12 & 2 \\
pUB112 & 1 & 0 & 1 & 0 & 0 & 1 & 2 & 4 & 0 & 0 & 0 & 7 & 0 \\
pSK103 & 0 & 1 & 1 & 1 & 0 & 1 & 1 & 4 & 0 & 0 & 0 & 11 & 0 \\
pC223 & 0 & 1 & 1 & 1 & 0 & 1 & 1 & 4 & 0 & 0 & 0 & 12 & 0 \\
\hline
\end{tabular}

* No sites were detected on any of the plasmids for the restriction endonucleases $B a m H I, B g I, E c o R V$, HaeIII, HpaI and KpnI.

pSK103 possesses a single recognition site for HindIII (table II); however, HindIII-HpaII double digestion easily differentiated pSK2 from pSK103; the digestion products of pSK 2 were $2 \cdot 1,1.85$ and $0.55 \mathrm{~kb}$ (fig. 1 , lane a) whereas those of pSK 103 were 4.2 and $0.4 \mathrm{~kb}$ (fig. 1, lane d). In contrast, pSK 5 and

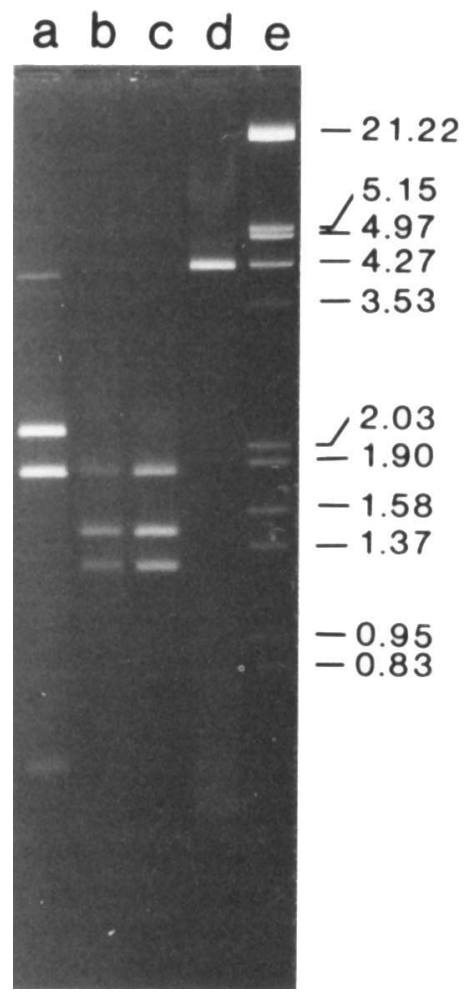

Fig. 1. Agarose gel $(1.6 \% \mathrm{w} / \mathrm{v})$ electrophoresis of purified staphylococcal DNA cleaved with the restriction endonucleases HindIII and HpaII: Lanes (a) pSK2; (b) pSK5; (c) pSK102; (d) pSK 103; (e) lambda phage DNA cleaved with HindIII and EcoRI as standards. Fragment sizes (in $\mathrm{kb}$ ) are shown on the right. The faint bands present in lanes (a) and (d) are incomplete digestion products.
pSK 102 were indistinguishable after double digestion with these endonucleases; both plasmids generated three fragments of $1.85,1.45$ and $1.25 \mathrm{~kb}$ (fig. 1, lanes $b$ and $c)$. They were distinct from pSK 2 and pSK 103.

Digestion of these plasmids with TaqI (fig. 2A) further substantiated the close relatedness of pSK 5 and pSK 102, and also revealed a relationship between these two plasmids and pSK2. Eight of the eleven TaqI fragments of pSK2 (table II) were clearly resolved in fig. 2A (lane a); the remaining three fragments were detected by polyacrylamide gels electrophoresed under conditions better suited to the resolution of fragments of less than $0 \cdot 1 \mathrm{~kb}$. TaqI digestion of pSK 5 and pSK 102 (fig. 2A, lanes $\mathrm{b}$ and $\mathrm{c}$ ) indicated that the two plasmids were identical. Ten of the twelve TaqI fragments of pSK 5 and pSK 102 (table II) have been resolved; it should be noted that four fragments of $1 \cdot 16,0.47,0.28$ and $0.11 \mathrm{~kb}$ were equivalent in size to fragments generated from pSK2. The TaqI profile of pSK 103 (fig. $2 \mathrm{~A}$, lane $\mathrm{f}$ ) revealed that this plasmid, while possessing eleven $T a q$ I sites (table II), was not related to pSK2, pSK 5 or pSK 102.

TaqI restriction profiles were also used to compare the four $\mathrm{Cm}^{\mathrm{r}}$ plasmids isolated from Australian strains of $S$. aureus and $S$. epidermidis with three $S$. aureus $\mathrm{Cm}^{\mathrm{r}}$ plasmids (table I) isolated elsewhere. Plasmids pSK5 and pSK102 had TaqI fragments of electrophoretic mobility identical to those fragments derived from pC221 (fig. 2A, lane d) and each of these plasmids, together with pSK2, shared several fragments of similar size with pUB112 (fig. 2A, lane e). The $S$. epidermidis $\mathrm{Cm}^{\mathrm{r}}$ plasmid pSK 103 was found to have nine TaqI restriction fragments in common with pC223 (fig. $2 \mathrm{~A}$, lane g), two of which form a doublet of $c .0 \cdot 25 \mathrm{~kb}$ in size.

The analysis of the seven $\mathrm{Cm}^{\mathrm{r}}$ plasmids was 

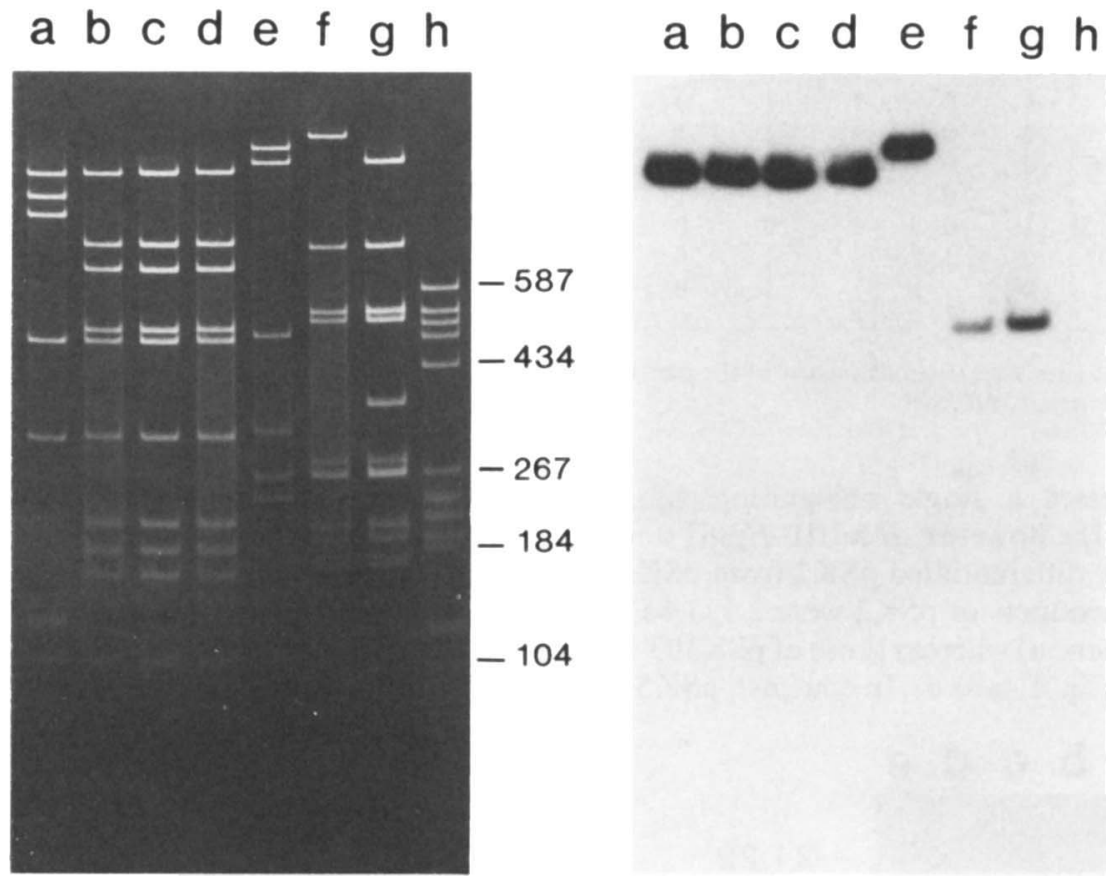

Fig. 2. (A). Polyacrylamide gel $\left(6^{\prime \prime}, \mathrm{w}\right.$ : v) electrophoresis of purified staphylococcal DNA cleaved with the restriction endonuclease Taql: Lanes (a) pSK2: (b) pSK5: (c) pSK 102; (d) pC221: (e) pUB112; (f) pSK 103; (g) pC223; (h) pBR322 cleaved with Haelll as standards. Sizes of selected fragments (in base pairs) are shown on the right. The sixth band from the well in lanes (a) and (f) and the seventh band from the well in lane $(\mathrm{g})$ are doublets: these fragments, together with Taql digestion products $<0 \cdot 1 \mathrm{~kb}$. have not been clearly resolved in this gel. (B) Autoradiograph of gel shown in (A) after hybridisation with a radiolabelled cat probe derived from pC221 as described in the text. No homologous sequences were detected in lane (h).

extended by restriction site mapping with Taql and a further twelve endonucleases (table II). Double digestion with appropriate combinations of these endonucleases enabled the order and position of recognition sites within a particular plasmid to be established (fig. 3). The restriction endonuclease maps determined for plasmids pSK 5 and pSK 102 were indistinguishable from each other and from that of $\mathrm{pC} 221$ and we conclude that these three plasmids are identical. Although some uncertainty remains as to the relative positions of seven identically-sized TaqI fragments of pSK 103 and pC223 (fig. 3), the restriction maps of these plasmids were identical, with the exception of an additional TaqI site on $\mathrm{pC} 223$.

\section{Hybridisation analysis of the staphylococcal $\mathrm{Cm}^{r}$ plasmids}

Restriction endonuclease mapping suggested that a region of homology was shared by the $\mathrm{Cm}^{\mathrm{r}}$ plasmids pSK2, pSK5/pSK 102, pC221 and pUB112 (fig. 3). The common DNA sequences, located approximately between the $\mathrm{Taq}$ I sites at coordinates 0.5 and 2.53 on the pSK 2 map, specify the replication functions (REP D) and an inducible chloramphenicol acetyltransferase (CAT) in pC221 (Brenner and Shaw, 1985) (fig. 3).

The possibility that the $\mathrm{Cm}^{\mathrm{r}}$ plasmids pSK2, pSK5/pSK 102, and pUB 112 carried the same cat gene as pC221 was confirmed by hybridisation experiments. The TaqI digests of the $\mathrm{Cm}^{r}$ plasmids (fig. 2A) were hybridised with a ${ }^{32} \mathrm{P}$-labelled probe consisting of the $0.43-\mathrm{kb} \mathrm{AccI-MboI}$ fragment of pC221 which comprised a large portion of the cat gene (fig. 2B). As could be predicted from the restriction endonuclease maps (fig. 3 ), the largest TaqI fragment of each of pSK2, pSK5/pSK 102, pC221 and pUB112-all of which contain the sequence encompassing the common Accl, BstEll and $M b o I$ recognition sites-hybridised with the probe (fig. 2B, lanes a-e). Unexpectedly, a $0 \cdot 5-\mathrm{kb}$ 


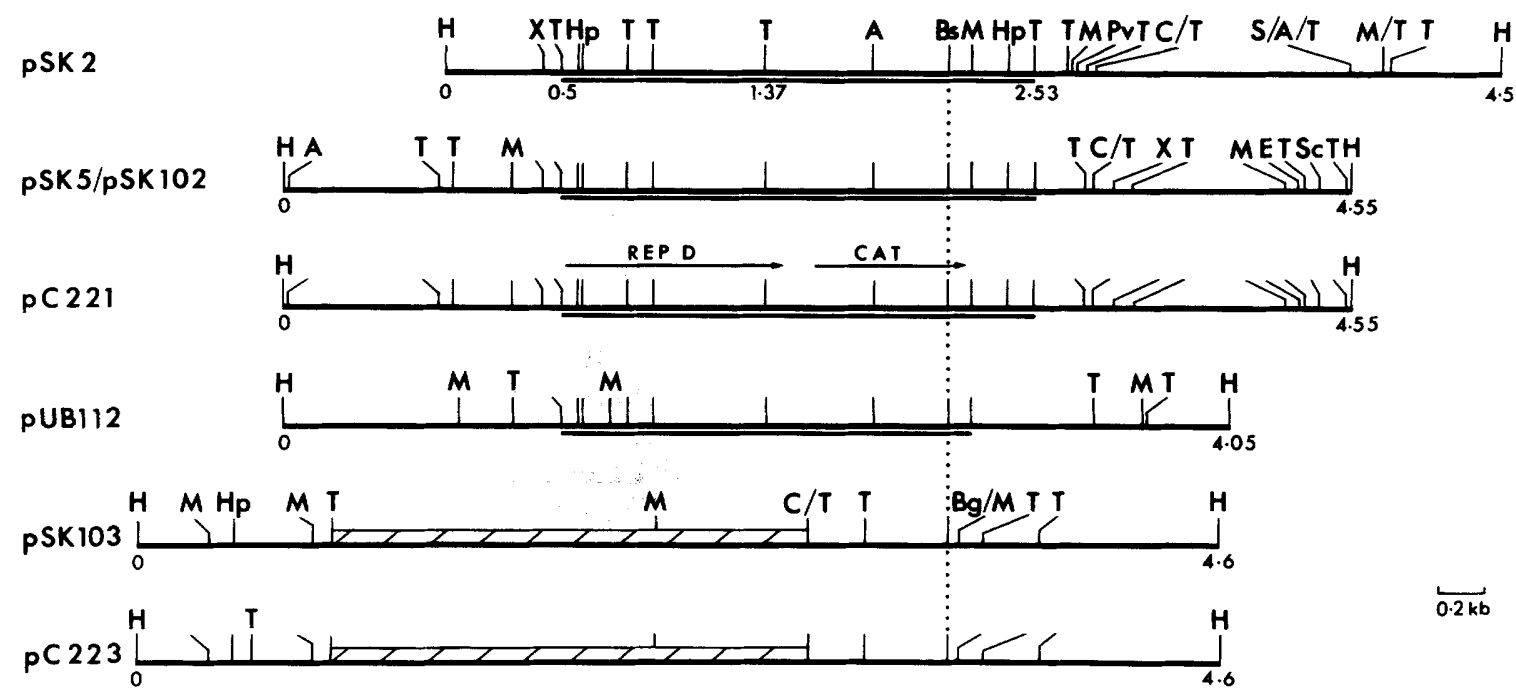

Fig. 3. Restriction endonuclease maps of $\mathrm{Cm}^{r}$ plasmids from $S$, aureus (pSK2, pSK5, pC22I, pUB1 12 and pC223) and $S$. epidermidis (pSK 102 and pSK 103). The unique HindIII site was chosen as the reference point $(0 \mathrm{~kb})$ for all plasmid maps which have been aligned by reference to the single $B s t$ EII site present on each. Areas of restriction identity between pSK 2 , pSK $5 / \mathrm{pSK} 102$, pC221 and pUB 112 , as referred to in the text, are indicated by underlining; hatching denotes the identical $2 \cdot 11-\mathrm{kb}$ regions of pSK 103 and $\mathrm{pC} 223$ that contain six unmapped TaqI sites. Regions of $\mathrm{pC} 221$ which specify the protein required for replication (REP D) and the inducible chloramphenicol acetyltransferase (CAT), as described by Brenner and Shaw (1985) and Projan et al. (1985), are shown; the direction of transcription of these regions is indicated by the arrowheads. Restriction endonuclease sites are designated: A, $A c c \mathrm{I}$; Bg, BglII; Bs, Bst EII; C, ClaI; E, EcoRI; H, HindIII; Hp, HpaII; M, MboI; Pv, PvuII; S, SalI; Sc, SacI; T, TaqI; X, XbaI. Map coordinates are in kilobase pairs. Only those TaqI sites of pSK 2 referred to in the text have been assigned coordinates.

TaqI fragment and, at a very low level, a $0 \cdot 25 \mathrm{~kb}$ TaqI fragment, of both pSK 103 and pC223 were found to hybridise with the $\mathrm{pC} 221$-derived probe (fig. 2B, lanes $f$ and $g$ ). Only the position of the larger of these has been mapped on pSK 103 and pC223; it contained the recognition sites for BstEII and $B g / \mathrm{II} / M b o \mathrm{I}$ which are approximately 50 base pairs apart (fig. 3).

The epidemiology of $\mathrm{Cm}^{\mathrm{r}}$ plasmids was assessed in more than 50 nosocomial isolates of $\mathrm{Cm}^{\mathrm{r}}$ coagulase-negative staphylococci. Hybridisation analysis of these strains indicated that approximately half carried a $4 \cdot 5-\mathrm{kb}$ plasmid with a pC221-like cat gene, whereas the remainder harboured a plasmid of similar size which resembled pSK 103 in its response to the pC221-derived cat probe.

\section{Discussion}

The $\mathrm{Cm}^{\mathrm{r}}$ plasmids characterised in this study were divided into two groups on the basis of restriction endonuclease fingerprinting and DNADNA hybridisation. The first group comprised the identical plasmids pSK5 and pSK 102, from $S$. aureus and $S$. epidermidis, respectively, together with the $S$. aureus plasmid pSK2. Each possessed DNA sequences homologous with those that encode CAT on the $S$. aureus $\mathrm{Cm}^{\mathrm{r}}$ plasmids pC221 and
pUB112. DNA-DNA heteroduplex analyses support the absolute identity of pSK2 and pC221 over the cat sequences and, in agreement with the restriction mapping data presented, extend the homology between these two plasmids to include the DNA sequences that encode replication functions (Tennent, May and Skurray, unpublished data).

Subsequent to this study, the complete nucleotide sequence of pC221 was reported (Brenner and Shaw, 1985; Projan et al., 1985), as was a restriction map of pUB112 (Brückner et al., 1984). With the exception of an undetected 16 base pair HpaII fragment, the presence of which was inferred on pSK 2, pSK 5, pSK 102 and pUB112 from the pC221 sequence (table II; fig. 3), our data were in total accord with this published information.

The remaining $\mathrm{Cm}^{\mathrm{r}}$ plasmid, pSK 103, detected in $S$. epidermidis, closely resembled the $S$. aureus plasmid pC223. With the exception of a single Bst EII site, which was present on all of the $\mathrm{Cm}^{\mathrm{r}}$ plasmids studied, the restriction maps of pSK 103 and $\mathrm{pC} 223$ were dissimilar from those constructed for the pC221-like plasmids. Nevertheless, heteroduplex studies and DNA sequence data will ultimately be required to determine the relatedness of members of the two groups because disparate restriction maps may arise from closely related 
plasmids via the effects of minor alterations to the DNA sequences.

The presence of common antibiotic resistance plasmids has previously been reported for strains of $S$. aureus and $S$. epidermidis resistant to penicillin (Totten et al., 1981), tetracycline (Groves, 1979: Cooksey and Baldwin, 1985) or gentamicin (Cohen et al. 1982; Jaffe et al.. 1982; Archer and Johnston, 1983). Our results show that similar, and in some cases identical, $\mathrm{Cm}^{r}$ plasmids are associated with multiresistant $S$. aureus and $S$. epidermidis strains isolated from Australian hospitals. Taken together, these observations strengthen the role of $S$. epidermidis as a possible reservoir of resistance determinants which are available for transfer to $S$. aureus.

\section{REFERENCES}

Archer G L, Johnston. J L 1983 Self-transmissible plasmids in staphylococci that encode resistance to aminoglycosides. Antimicrobial Agents and Chemotherapy 24:70-77.

Brenner D G. Shaw W V 1985 The use of synthetic oligonucleotides with universal templates for rapid DNA sequencing: results with staphylococcal replicon pC221. EMBO Journal 4:561-568.

Brückner R. Zyprian E. Matzura H 1984 Expression of a chloramphenicol-resistance determinant carried on hybrid plasmids in Gram-positive and Gram-negative bacteria. Gene 32: $151-160$.

Cohen M L, Wong E S, Falkow S 1982 Common R-plasmids in Staphylococcus aureus and Staphylococcus epidermidis during a nosocomial Staphylococcus aureus outbreak. Antimicrobial Agents and Chemotherapy $21: 210-215$.

Cooksey R C. Baldwin J N 1985 Relatedness of tetracycline resistance plasmids among species of coagulase-negative staphylococci. Antimicrohial Agents and Chemotherap! 27:234-238.

Daniels D L. Schroeder J L. Szybalski W, Sanger F. Blattner F R 1983 A molecular map of coliphage lambda. In: Hendrix RW, Roberts J W. Stahl F W, Weisberg R A (eds) Lambda II, Cold Spring Harbor Laboratory, Cold Spring Harbor. New York, p 469-517.

Gillespie M T. May J W. Skurray R A 1984 Antibiotic susceptibilities and plasmid profiles of nosocomial methicillin-resistant Staphylococcus aureus: a retrospective study. Journal of Medical Microbiology 17:295-310.

Groves DJ 1979 Interspecific relationships of antibiotic resistance in Staphylococcus sp.: isolation and comparison of plasmids determining tetracycline resistance in $S$. aureus and S. epidermidis. Canadian Journal of Microbiology 25: 14681475.

lordảnescu S. Surdeanu M. Della Latta P. Novick R 1978 Incompatability and molecular relationships between small staphylococcal plasmids carrying the same resistance marker. Plusmid 1:468-479.

Jaffe H W. Sweeney H M. Weinstein R A. Kabins S A. Nathan C. Cohen S 1982 Structural and phenotypic varieties of gentamicin resistance plasmids in hospital strains of Staphylococcus aureus and coagulase-negative staphylococci. Antimicrohial Agents and Chemotherapy 21:773 779.

Lyon B R, Iuorio J L. May J W, Skurray R A 1984a Molecular epidemiology of multiresistant Staphylococcus aureus in Australian hospitals. Journal of Medical Microbiology 17:79-89.
Likened to conjugation, the exact mechanism by which interspecific transfer occurs amongst the staphylococci remains unclear. However, the transfer of resistance plasmids from $S$. epidermidis to $S$. aureus has been demonstrated in vivo (Naidoo, 1984), thus implicating the natural habitat of these organisms as a factor involved in genetic transfer.

We thank $\mathrm{Mr} M$. Gillespie for providing comparative restriction map data for pC223 before publication, and together with Mr B. Lyon, for helpful discussions. We are grateful to our colleagues in the Bacteriology Department. Prince Henry's Hospital. Melbourne, for providing clinical isolates of staphylococci. This work was supported by a Project Grant from the National Health and Medical Research Council of Australia.

Lyon B R, May J W, Skurray R A 1983 Analysis of plasmids in nosocomial strains of multiple-antibiotic-resistant Staphylococcus aureus. Antimicrobial Agents and Chemotherapy 23:817-826.

Lyon B R. May J W, Skurray R A 1984b Tn4001: a gentamicin and kanamycin resistance transposon in Staphylococcus aureus. Molecular and General Genetics 193:554 556.

Maniatis T. Fritsch E F. Sambrook J 1982 Molecular cloning: a laboratory manual. Cold Spring Harbor Laboratory, Cold Spring Harbor. New York.

McDonnell R W. Sweency H M. Cohen S 1983 Conjugational transfer of gentamicin resistance plasmids intra- and interspecifically in Staphylococcus aureus and Staphylococcus epidermidis. Antimicrobial Agents and Chemotherapy 23: $151-160$.

Naidoo J 1984 Interspecific co-transfer of antibiotic resistance plasmids in staphylococci in vivo. Journal of Hygiene. Cambridge 93: 59-66.

Novick R P 1976 Plasmid-protein relaxation complexes in Staphylococcus aureus. Journal of Bacteriology 127:1177. 1187.

Projan S J, Kornblum J, Moghazeh S L, Edelman I, Gennaro M L, Novick R P 1985 Comparative sequence and functional analysis of pT181 and pC221, cognate plasmid replicons from Siaphylococcus aureus. Molecular and General Geneiics 199:452-464.

Shaw W V 1984 Bacterial resistance to chloramphenicol. British Medical Bulletin 40:36-41.

Smith H O 1980 Recovery of DNA from gels. Methods in Enzlymology 65:371-380.

Smith G E. Summers M D 1980 The bidirectional transfer of DNA and RNA to nitrocellulose or diazobenzyloxymethylpaper. Analytical Biochemistry 109: 123-129.

Sutcliffe J G 1978 pBR322 restriction map derived from the DNA sequence: accurate DNA size markers up to 4361 nucleotide pairs long. Nucleic Acids Research 5:2721-2728.

Tennent J M. May J W. Skurray R A 1984 Multiple antibiotic resistance in Staphylococcus aureus and Staphylococcus epidermidis: plasmids in strains associated with nosocomial infection. Pathology 16:250-255.

Totten P A, Vidal L, Baldwin J N 1981 Penicillin and tetracycline resistance plasmids in Staphylococ'cus epidermidis. Antimicrobial Agents and Chemotherapy 20:359-365.

Wilson C R, Baldwin J N 1978 Characterization and construction of molecular cloning vehicles within Staphylococcus aureus. Journal of Bacteriology 136:402-413. 